\title{
EVALUATING RESTORATIVE JUSTICE PROGRAMS
}

Derek R. Brookes

\author{
Marat \\ these calls of the inner self \\ are worse than the deepest stone dungeon \\ and as long as they are locked \\ all your revolution remains \\ only a prison mutiny \\ to be put down by corrupted fellow prisoners. \\ Peter Weiss, Marat/Sade
}

\section{INTRODUCTION}

Restorative Justice is a philosophical and programmatic alternative to the goals and procedures which characterize the present-day criminal justice system. The primary site for restorative justice is not a court of law, a prison cell, a boot-camp, or an execution chamber. It is a mediated encounter between those directly involved in or affected by the crime: the victim, the offender, family members, and community representatives. The principal aim of these encounters is to facilitate the following three processes:

${ }^{-}$Reconciliation: where the victim and offender--in the social rituals of apology and forgiveness --(i) offer and receive the value and respect owed in virtue of their intrinsic human dignity and worth, and (ii) engage in a mutual condemnation of the criminal act, whilst ceremonially 'casting off' or decertifying the offender's deviant or blameworthy moral status.

- Reparation: where the offender takes due responsibility for the crime by 'making good' the material harm done to the victim: that is, by agreeing to provide a fair and mutually acceptable form of restitution and/ or compensation.

And, as an ongoing consequence of reconciliation and reparation:

- Transformation: where the individuals and communities concerned experience some degree of liberation from the conditions that perpetuate the cycle of violence, aggression, and domination exemplified in criminal behavior: for example, by overcoming the negative emotions of humiliation, fear and hatred, and by advancing the alleviation of various 
forms of degradation, oppression and stigmatization which characterize socio-political structures and interpersonal relations.

\section{THE CRITIQUE OF RETRIBUTIVISM}

The theory of restorative justice centers its critique of the present criminal justice system on what it sees as the 'internal problematic' of the theory of retributivist justice. Most retributivists would tend not to locate any 'unsolved problem' in their core values and principles: whatever else is wrong with the theory, they might say, the 'just deserts' principle is philosophically sound. However, almost every retributivist is deeply troubled by current attempts to apply this principle within the current criminal justice system. For example, a convicted criminal is called a "client," rather than "the person to be punished," an "inmate" rather than a "prisoner," judges do not sentence a person to "pain," but to various "measures," and there is little discussion of the "core phenomena," namely, the penalties themselves. There are no descriptions of what punishments feel like, how much they hurt, the suffering and the sorrow experienced by the prisoner, the harmful effects that his imprisonment may have on his family and loved ones.

The theory of restorative justice does not begin its critique of retributivism with an abstract analysis of various philosophical or legal theories of punishment. It does not, in other words, accept attempts to draw clean distinctions between the philosophical plausibility of the retiributivist theory, and the ethical status of the practices it has inspired and the condition of the lives it has affected. On the restorative view, advocates of a theory of justice must show that its values and normative prescriptions might be successfully implemented in this world, in this socioeconomic context, with this set of economic, educational, race, and gender inequities, in this politically driven bureaucracy. In abstraction, the retributivist principle of deserved punishments is beautifully simple and compelling. But as soon as one attempts to provide a map of how the principle might be embodied in social and experiential reality, one is faced with criminals who never quite fit the juridical model of the rational, autonomous individual; and the imposition of punishment never quite seems to leave the sharp-edged, unambiguous impression that the human suffering and pain thereby inflicted on the individual is precisely what he or she deserved.

\section{THE BASIS FOR RECONCILIATION}

It is in its self-conscious attempt to ensure that its core values are indeed situated in social and experiential reality, that the theory of restorative 
justice transcends the retributivist theory. The human dimensions involved in the operational objectives of Restorative Justice therefore demand the highest quality of program design and staff training (Marshall \& Merry, 1990: 104). Specifically, victim-offender encounters must be designed, facilitated and evaluated in such a way as to ensure that they are clearly oriented toward the accomplishment of Restorative Justice-in all its richness and complexity. In this paper, I argue that this desideratum has yet to be fully realized in existing Restorative Justice programs, in particular, with regard to the facilitation of reconciliation.

I begin by presenting the chief problems associated with the concentration on reparation in Restorative Justice programs, to the neglect of reconciliation. I then argue that this phenomenon is, in part, a consequence of (i) the almost universal use of service-delivery criteria in the evaluation of Restorative Justice programs, and (ii) the absence of research on the interactional processes involved within the victimoffender encounter itself, using suitably designed methodological tools.

\section{RE-VICTIMIZATION}

A commonly reported feature of victim-offender encounters is that their structure, content, mediator orientation, and evaluative criteria are dominated by the goal of reparation (Gehm, 1990: 179; Van Ness \& Strong, 1997: 71; Retzinger \& Scheff, 1996: 317). Without denying its essential role, (Marshall \& Merry, 1990: 100; Davis et.al., 1992: 457) this concentration on reparation has led to several counter-restorative outcomes. First, a restitution or compensation agreement may achieve the restoration of equity; but if the offender remains hostile, unrepentant, and disrespectful, then the victim may view the settlement with resentment, dissatisfaction, and a sense of arbitrariness (Marshall \& Merry, 1990: 98). Umbreit's study found that some victims did not find the mediation "helpful," due to the "negative, non-repentant attitude of their specific offender. 'I felt he wasn't owning up to it.' 'He just slouched all the way down, and just sat and half-heartedly gave answers'." (Umbreit, 1990:56)

Second, the offender may regard the reparation not as an expression of his remorse, his desire to "make things right," but rather as a punitive or retributive measure (Blagg, 1985; Marshall \& Merry, 1990: 99). Indeed, both parties are likely to leave not only with their stigmatized statuses of "victim" and "offender" reinforced, but now with additional nuances: the offender might now regard the victim as the "privileged avenger," and himself as a "victim" of the justice system. Even the social rituals involved in reconciliation, poorly handled, may be conceived as 
punitive (Blagg, 1985, quoted in Davis et.al., 1992:143). The victim may see herself as having been re-victimized by the process, and the unrepentant offender as "irredeemably evil." These are precisely the kinds of experiences which characterize the existing criminal justice process, and which victim-offender encounters were designed to avoid or ameliorate.

\section{AVOIDANCE OF "HARD CASES"}

Restorative Justice advocates often argue that victim-offender encounters should be restricted to property offenses, burglaries, and other "minor" crimes (Conrad, 1990:320; Marshall \& Merry, 1990:3). There are several explanations for this restriction. First, it is often thought that some crimes are so "heinous" or damaging to the person, that any apology, no matter how sincere, would be contemptuous, even repulsive; likewise, the suggestion that victims ought to forgive crimes of rape, incest or murder would seem callous in the extreme, and may only increase their suffering and magnify the violation they feel (Tavuchis, 1991:21).

Second, it may be thought that, in such cases, no amount of reparation could conceivably compensate for the harm done; and any attempt to suggest that it could is, again, likely to perpetuate and amplify the harm (Marshall \& Walpole, 1985: 46; Reeves, 1989:47; Hudson, 1990:274). This view is not, in itself, inconsistent with the perspective that an exclusive focus on reconciliation, in such cases, would be the appropriate restorative response. However, if a Restorative Justice program has designed the basic structure of its victim-offender encounters so as to be oriented toward the primary objective of reaching a reparation agreement, then it might tend to shy away from encounters which, due to the nature of the crime, would fail to satisfy their chief desideratum (Marshall \& Merry, 1990:179; Umbreit, 1994: 58).

Third, the neglect of serious cases, may be due to severe theoretical limitations in the restorative conceptualization of crime. The retributivist theory of criminal justice is sometimes criticized on the grounds that "the dangerous offender" or "the heinous crime" is taken as the base-line standard or norm for dealing with all crimes. The result of this limitation is that long-term incarceration, with its dual restraining and condemnatory function, has become the punishment of choice, regardless of its appropriateness in individual cases (Zehr, 1990: 180). However, some restorative theoreticians may have reacted by simplifying the baseline norm in the opposite extreme, that is, by designing normative procedures for responding to crime which are based upon the kind of petty offense performed by an adolescent living in a white, suburban, middle class, church-going, and otherwise loving family. This is no 
hyperbole: taking the 'family model' as the norm is explicit in much of the restorative literature (Braithwaite, 1989: 56).

Fourth, Restorative Justice programs often acknowledge the importance (and the possibility) of reconciliation in the more serious cases; but then argue that a victim-offender encounter may not be the most appropriate process to accomplish this end. The hostility and vengefulness of the victim, coupled with the coldness or indifference of the offender, would be such that any confrontation would only exacerbate the "ill-feeling" or "raise the temperature" (Marshall \& Merry, 1990: 191; Dongier \& Doosselaere, 1992: 507-8) Umbreit reports the following explanations given by victims who chose not to participate: "I didn't want to see him because I would get mad." "This kid is so terrible and mean ... flipping me off. . I didn't want to ever see this jerk" (1994: 58) However, this response betrays a conceptualization of the reconciliation process as akin to the relatively quick and cool-headed negotiation of a restitution settlement (Gronfors, 1992: 423). It may be that reconciliation, in some cases, is comparatively swift and painless. But, as Marshall and Merry suggest, it is precisely those parties who exhibit intense hostility or cynical indifference that may be in the greatest need of a skillfully mediated victim-offender encounter if they are ever to achieve genuine reconciliation.

Victim fear and anger are often given as reasons for not going ahead with mediation. Obviously one does not want to precipitate a violent episode, but such feelings, if not too extreme, can be dealt with by a properly skilled mediator. They are coped with all the time in divorce mediation. Strong feelings may have a greater capacity for impressing the offender if channeled in a constructive way. They may mean there is more to resolve and hence more to achieve. . Most of the meetings we have documented have not been pitched at a high emotional level, and the victims involved, at least by the time the meeting took place, were not feeling overwhelming despair or anger. They were more inconvenienced than traumatized. This may be partly a matter of case-selection, partly a matter of timing. As a result we have yet to see the full power of mediation between victim and offenders, or to see this tested out, except in a few atypical cases (Marshall \& Merry, 1990: 183).

Fifth, it may be argued that victims who display considerable "hurt, anger or anxiety" would be "emotionally unprepared for a confrontation with their offender." In other words, a victim-offender encounter, under such conditions, would create a high risk of 
revictimization- "harming victims through making demands with which they could not cope." But it does not follow straightforwardly that victims should, for this reason, be denied access to an encounter; rather victims should, in such cases, be provided with "the support and preparation that would enable them to take advantage of the mediation process, to turn it to their best interests" (Marshall \& Merry, 1990: 246).

However, this provision of additional "support and preparation" must be strongly qualified: the actual encounter between victim and offender must, even in the more difficult cases, be regarded as the primary site for achieving the goals of Restorative Justice. For example, mediators may take very seriously the task of eliciting genuine remorse in the offender, but then do all of the facilitory work prior to the meeting (Davis et.al., 1992: 95, 98). The inevitable result is that the ritual of apology, when finally performed within the mediation session, comes across as highly rehearsed, superficial and perfunctory--as if in a formal court hearing (Davis et.al., 1992: 157); and the full potential of the encounter for eliciting a dynamic, powerful, and genuinely healing interaction is thereby lost. The one feature which makes the victim-offender encounter a unique, non-reproducible alternative, is exchanged for the safe haven of predictability (Davis et.al., 1992:155).

Finally, Restorative Justice programs might concede all this, and yet argue that the long-term commitment required to facilitate the process of reconciliation in such cases, would exceed the resources of typical victim-offender programs. Take, for example, Marshall and Merry's recommendation:

Where complex and long-standing relationship problems were involved it would seem better to concentrate on relatively simple points of disagreement, usually pertaining to the commission of the offence, on which some kind of settlement in the short term is feasible. More fundamental reconciliation in such cases would involve longer-term counseling of each party separately, involving an escalation of effort beyond that which is economically feasible. It seems more sensible for schemes to take as their aim the facilitation of short term engagement between estranged parties in order to provide a constructive platform for the development of future relations, rather than take responsibility for trying to reconcile parties in more diffuse terms. The experience of mediation itself may provide people with the reorientation of attitudes and skills to make progress of their own accord. Ultimately that is, in any case, the only sound foundation for a successful relationship: one cannot always be 
seeking out a mediator to sort out every little difficulty!

(Marshall \& Merry, 1990: 227)

This argument, however, is a non sequitur: in those cases where an encounter on its own is sufficient to provide the skills and elicit the desire for "private" reconciliation, or where the difficulty is, indeed, "little," then there would be no need for longer-term commitment by the program. But these are not the cases at issue here. As Marshall and Merry acknowledge, the more extreme forms of estrangement will require ongoing, intensive support-from a variety of resources-if any kind of reconciliation is to be achieved.

The question at issue, then, is this: if reconciliation is regarded as a primary social good, a good without which individuals are likely to be consumed by hatred or guilt, or grow cold with cynicism and indifference; if there is clear evidence that, without a mediated encounter or ongoing community support, both victim and offender will continue in a state of alienation from each other and from society, then, to dismiss such cases as "too hard" or "too expensive" is not only indicative of a failure to take seriously the primary goal of Restorative Justice, but also a failure of social conscience and human compassion (Peachey, 1990: 556; Trenczek, 1990:120).

\section{SERVICE-DELIVERY EVALUATIVE CRITERIA}

One explanation for the concentration on reparation, and the ambivalence about casting reconciliation as a primary goal, might be found in the methodologies typically used to evaluate restorative programs. The majority of published (and unpublished) evaluative research has focused almost exclusively on the social service features of victim-offender encounters. A good example of the service-delivery evaluative framework is Mark Umbreit's "two-and-one-half-year study of victim-offender mediation programs in California, Minnesota, New Mexico, and Texas. Without wishing to deny its value, the study's research questions were evidently designed to evaluate the satisfaction of one or more of the three types of social service criteria (1994:31-32). In other words, the evaluative criteria of this research has typically been restricted to delivery efficiency (e.g. costs per case), effort (e.g. caseloads per mediator), and outcome (e.g. percentage of agreements, satisfaction of disputants, restitution compliance rates) (Lowry, 1993: 117). I select Umbreit largely because his research methodology is both well-known and representative of the majority of research on victim-offender mediation.

There are several reasons for this restriction. First, to justify their existence and funding, victim-offender programs have appealed to the persuasive power of utilitarian or economic rationalism (Marshall \& 
Merry, 1990: 16-17): victim-offender encounters are advanced as preferable alternatives to the traditional criminal justice process on the grounds that (i) they will decrease court caseloads, the prison inmate population, and recidivism rates; and (ii) they will increase the percentage of restitution settlements and victim/offender satisfaction.

Second, most of the data relevant to service-delivery criteria is comparatively easy to collect: minimal requirements for program management will involve keeping records of costs per case, caseloads, referral sources, types of cases, percentage of settlements reached, and, with a little more effort, percentage of restitution compliance and participant satisfaction. Third, it is, as a consequence, relatively cheaper to produce program evaluations using service-delivery data. Finally, the audience for which these evaluations are primarily designed-funding agencies, policy makers, and criminal justice professionals-do not generally require, and would not necessarily appreciate or acknowledge more qualitative or substantive data (Lowry, 1993:119; Marshall \& Merry, 1990:31,25)

The problem with this restriction, however, is that even if these criteria were shown to be satisfied, such an evaluation would tell us almost nothing about the more substantive claims made for victimoffender encounters (Wright, 1991: 537): how would we know, on the basis of service-delivery data, whether a particular encounter has, indeed, "given participants access to a higher quality of justice," "evoked genuine remorse in the offender," "enabled the victim to overcome her resentment, fear and negative self-identity," "repaired the social bonds", "shamed the offender within a continuum of love and respect," "decertified his deviant status," and so on? And until such information is forthcoming--that is, in non-anecdotal form-there remains little basis for the claim that victim-offender encounters are theoretically grounded in the social and experiential reality of its participants (Umbreit, 1994:6).

Take the criterion of agreement percentages. This is perhaps the most widely used source of evidence for the success of victim-offender encounters. But what does the fact of an agreement tell us about the more substantive issues? First, if the parties have agreed to participate in a mediation session, they will already be sufficiently motivated to achieve some kind of settlement. Second, an agreement may vary to an enormous degree in terms of its significance for the participants; and this may be impossible to determine by reference either to the fact of an agreement or to its content. For example, the "settlement" may involve a simple apology, substantial monetary restitution, a signed pledge to perform community service, an agreement to have nothing to do with each another from this point on, and so forth. The problem is that any one of these forms of reparation may represent a substantial breakthrough in terms of 
reconciliation. On the other hand, the agreements may be token offerings to "get the thing over with" lacking any reconciliatory purpose. In sum, an encounter might be classified as "a success" on service-delivery grounds, and yet fail entirely to accomplish the primary goal of Restorative Justice. Alternatively, it may be classed as a "failure' due to the lack of any significant reparation settlement, and yet the participants may have nevertheless experienced reconciliation (Marshall \& Merry, 1990:30).

It might be argued that political and financial constraints demand that the evaluation of victim-offender programs be construed within the service-delivery framework. This would not prevent mediators from pursuing the goal of reconciliation; but this further aim should not be construed-at least not publicly-as a primary objective or as an indicator of success. A good example of this strategy is Umbreit's "Sample Victim Information Letter"; In the letter, various reasons are given for why the victim might wish to participate in a mediation session:

$[R]$ eceive answers to questions about the offense that only the offender can provide"; "express your frustration and concerns directly to the person who should hear them--the offender"; "become directly involved in the sentence your offender receives, rather than sitting on the sidelines"; "determine the amount and form of restitution to cover your losses through a structured meeting with the offender, in the presence of a trained mediator (Umbreit, 1994: 207).

On the basis of this list, it would be difficult for the victim to avoid the impression that the primary goal of the meeting is personal retribution and mediator-assisted reparation: victims are promised an opportunity to direct their negative emotions against the offender, to become personally involved in determining his punishment, and to negotiate a settlement to recover their losses. The terms "apology", "forgiveness," "reconciliation," and the like, are never mentioned-and deliberately so, it seems. A "Note to Program Staff," located beneath the sample, reads: "Be aware that the word "reconciliation" can push buttons and irritate some victims and many victim advocates" (Umbreit, 1994: 207).

Now Umbreit explicitly upholds reconciliation as the fundamental goal of victim-offender mediation (Umbreit, 1994: 363). But then, to entice victims to participate without faithfully representing the primary goal is highly questionable-even if the ultimate outcome is reconciliation (Centomani \& Dighera, 1992: 363). To do so by evoking attitudes, desires, and emotions which constitute the driving force behind that very paradigm of justice to which it is most strongly opposed, is straightforwardly disingenuous (Davis et.al., 1992: 92). 
Aside from the moral question, the problem with this strategy is that, in the long term, it will fail to achieve widespread acceptance of victim-offender encounters as a genuinely distinct alternative to the traditional criminal justice system. As Marshall and Merry suggest:

[I]f an innovation is to be acceptable as social policy, there must [among other things] . . . be a feeling that the provision of such services is obligatory upon society. . . In the [case of victim-offender mediation, research] would have to be able to demonstrate that the gains to victims from meeting their offenders were sufficiently substantial to encourage the growth of public feeling that such opportunities must be provided as of right ((Marshall \& Merry, 1990: 31).

But if the only evaluative research available is based upon criteria which could be equally well satisfied by existing social services or the civil law, then it is very hard to see how policy makers and the public are to be persuaded that this innovation should be accepted as social policy-particularly given the opposition it already faces from the dominant values of the current criminal justice system (Marshall \& Merry, 1990: 31).

\section{POST HOC EVALUATIVE DATA}

A second possible explanation for the ambivalence about reconciliation may lie in the methodological tools used to evaluate the mediation process. The majority of research on victim-offender encounters has concentrated on determining the impact of certain variables-such as the seriousness of the offence, mediator training, participant gender, race, age, and education - on various outcomes. Most of the data for this research consists either of transcriptions of audio-recordings or post hoc interviews and observer field notes, which are then interpreted, categorized and presented in narrative or statistical form (Pate, 1990:141; Umbreit, 1994; Leibrich, 1994).

The problem with this approach, however, is that these variables are situated within a highly complex sequence of interactional events. Their role in the mediation process - not to be identified with their role in the craft of post hoc narration-cannot therefore be explained unless they are examined as they occur in the context of the unfolding interaction. This is not to suggest that post hoc reports or interviews are of no value. But their significance is strictly limited to the understanding they provide of postmediation experiences: for example, the long-term effect of the encounter, the evolution of negative memories, the problems which arise due to inadequate 
follow-up ( Marshall \& Merry, 1990: 145, 147). Less charitably, they give us-above all-some degree of insight into the subjective "lens," the analytical imagination and the narration skills of the researcher. Note the vast distance between the mediation event as it actually occurs, and the event as constructed for the reader in the following description:

Four composite observations of mediation sessions will be presented in order to display a range of case examples involved in the mediation process. A qualitative analysis of the observations will then be presented, including a number of dangers and pitfalls. The four examples were constructed through identifying common characteristics among the total number of mediated sessions that were observed. Statements by participants that are presented in these examples are based on the actual mediations that were observed, although they are paraphrased (Umbreit, 1994, 119).

For example, take the following descriptions provided by various research studies. The first appears to be construed as a successful apology-forgiveness sequence; the second as an apology which elicits an affective response of some kind, perhaps forgiveness; the third appears to be "heard" as an insincere apology; and the fourth is construed as a heavily coached apology, with questionable effect.

Michael [the mediator] explained the reason for coming and then asked Mark to make his apologies. Somewhat cowed, Mark made a rushed and awkward statement -"Yeah, well, it was nothing personal, just happened to be your car-and I'm sorry." Mr. Symes thanked him for the apology (Marshall \& Merry, 1994: 54).

The stepfather points out to the offender that things could have been worse. 'You could have put out an eye; you could have blinded her.' 'I know. I know. That's why we were so scared,' the offender moans. 'I'm sorry it happened. It was stupid.' Both mothers are visibly moved by Brian's comments (Umbreit, 1994: 121).

After the breakdown of the system of justifications, Gerhard unexpectedly and long-windedly apologizes for his behavior. This, however, is questioned by the social worker since Gerhard did not avert the clash but instead also kicked the victim, who had already been knocked to the ground (Messmer, 1990: 67). 
We are ushered into the office of the Chief Ambulance Officer. He asks Gary [a juvenile offender] to sit rather than stand, perhaps wishing to avoid any impression of this being a dressing-down.-- David [a police sergeant]: "I think you have something to say to the officer, Gary."Gary mumbles what is presumably an apology. The Officer, apparently satisfied with Gary's effort, and rather embarrassed, says: "Fine, fine, I'm not here to tell you off because I realize you will have had your ear bent like that already' (Davis et.al., 1992: 56-7).

With only these post hoc narrations as evidence of the exchanges, we have no way of validating the researchers' interpretations of the events--e.g. "somewhat cowed," "awkward," "visibly moved," "moans," "long-windedly," "presumably an apology," "embarrassed," and so on. Nor can we determine the sequence of emotions, tones of voice, the interactional organization, or any other significant microfeature of the events, that might enable us to explain or understand the reconciliation process in anything but the most rudimentary fashion.

And we cannot rely instead upon studies of apology and forgiveness, as they occur in other contexts. Most studies of apology or forgiveness have either been based upon philosophical or religious reflection, or, like the evaluation of victim-offender encounters, have relied almost entirely upon post hoc data: that is, using questionnaires or interviews with the individuals concerned (or their therapists), narrations of psychotherapy case studies, psychotherapeutic or psychological constructions and discussions of relevant techniques, literary descriptions (fictional or historical), hypothetical role-plays or contrived incidents, post hoc records and linguistic analyses of trivial one-to-one remedial interchanges, or one-to-many public orations. No research study has yet examined the rituals of apology and forgiveness, as they actually occur, between criminal offenders and victims, within the setting of a mediated encounter.

In sum, research based upon post hoc evaluative data has not provided us with sufficiently reliable empirical evidence to support the more substantive claims made for victim-offender encounters: we know almost nothing of the interactional processes by which victim and offender mutually create a restitution agreement or perform the rituals of apology and forgiveness, or liberate one another from their stigmatized statuses of "victim" or "offender," and so on. Although Messmer used transcripts of audiotaped mediation conversations in order to "interpret the course of negotiation procedures between social worker, victim and offender"( 1990:471-72), the results suffer from brevity, narrowness of 
focus, and lack of reader-access to the original transcripts. As a consequence, Restorative Justice programs do not have adequate conceptual or methodological tools for coherent, systemic and empirically grounded mediator training and program design. Finally, the reliance on post hoc data has failed to provide the main stakeholders--funding agencies, policy makers, the general public, victims, offenders and their families - with anything but the vaguest, anecdotal understanding of the unique benefits of the victim-offender encounters, and the processes they are designed to facilitate (Marshall \& Merry, 1990: 26; Messmer \& Otto, 1992:8).

\section{CONCLUSION}

For the reasons outlined above, it is clear that the design and operation of Restorative Justice programs must be grounded upon a detailed theoretical and empirical study of the interactional processes involved in the social rituals of apology and forgiveness, as they occur within the context of victim-offender encounters. It is also clear that this kind of research has yet to be performed.

\section{REFERENCES}

Blagg, H. (1985) Reparation and Justice for Juveniles. British Journal of Criminology, 25, 267-279.

Braithwaite. J. (1989). Crime, Shame and Reintegration. New York, Cambridge University Press.

Centomani, P. \& Dighera, B. (1992) The new juvenile penal procedure code and the reparation-reconciliation process in Italy: A chance for a possible change. in H. Messmer \& H.-U. Otto (eds.), Restorative Justice on Trial: Pitfalls and Potentials of Victim-Offender Mediation: International Research Perspectives. Netherlands: Kluwer Academic Publishers, pp. 355-366.

Conrad, J. (1990) Concluding comments: VORP and the correctional future. In B. Galaway \& J. Hudson (eds.) Criminal Justice, Restitution and Reconciliation. Monsey NY: Criminal Justice Press, pp. 227-236.

Davis, G., Messmer, H. \& Umbreit, M. (1992) Making Amends: Mediation and Reparation in (riminal Justice. London and New York: Routledge.

Dongier, S. \& van Doosselaere, D. (1992) Approaching mediation in juvenile court: Rationale and methodological aspects, in H. Messmer \& H.-U. Otto (eds.), Restorative Justice on Trial: Pitfalls and Potentials of Victim-Offender Mediation: International Research Perspectives. Netherlands: Kluwer Academic Publishers, pp. 501-512. 
Gehm, J. (1990) Mediated victim-offender restitution agreements: An exploratory analysis of factors related to victim participation, in B. Galaway \& J. Hudson (eds.) Criminal Justice, Restitution and Reconciliation. Monscy NY: Criminal Justice Press, pp. 177-182.

Gronfors, M. (1992) Mediation: A romantic ideal or a workable alternative, in $\mathrm{H}$. Messmer \& H. U. Otto (eds.), Restorative Justice on Trial: Pitfalls and Potentials of Victin-Offender Mediation: International Research Perspectives. Netherlands: Kldwer Academic Publishers, pp. 419-430.

Hudson, J. (1992). A review of research dealing with views on financial restitution, in H. Messmer \& H.-U. Otto (eds.), Restorative Justice on Trial: Pitfalls and Potentials of Victim-Offender Mediation: International Research Perspectives. Netherlands: Kluwer Academic Publishers, pp. 239-276.

Leibrich, J. (1996). The role of shame in going straight: A study of former offenders, In B. Galaway \& J. Hudson (eds.) Restorative Justice: Intemational Perspectives Monesy, NY: Criminal Justice Press, pp. 283-302.

Lowry, K (1993). Evaluation of Community Justice Programs, in S. E. Merry \& N. Milner (eds.) The Possibility of Popular Justice: A Case Study of Community Mediation in the United States. Ann Arbor, MI: The University of Michigan Press, pp. 89-122.

Marshall, T. \& Merry, S. (1990). Crime and Accountability: Victim/Offender Mediation in Practice. Ilome Office, HMSO, London.

Marshall, I. \& Walpole, M. (1985). Bringing People Together: Mediation and Reparation Projects in Great Britain. Research and Planning Unit Paper 33. London: Home Office.

Messmer, H. (1990). Reducing the conflict: An analysis of victim-offender mediation as an interactive process, In B. Galaway \& J. Hudson (eds.) Criminal Justice, Restitution, and Reconciliation. NY: Criminal Justice Press, pp. 59-71.

Pate, Kim (1990). Victim-young offender reconciliation as alternative measures programs in Canada, in B. Galaway \& J. Hudson (eds.) Criminal Justice, Restitution, and Reconciliation. Monsey, NY: Criminal Justice Press, pp. 135144.

Peachey, D. E. (1992). Restitution, reconciliation, retribution: identifying the forms of justice people desire, in H. Messmer \& H.-U. Otto (eds.), Restorative Justice on Trial: Pitfalls and Potentials of Victim-Offender Mediation: International Research Perspectives. Netheriands: Kluwer Academic Publishers, pp. 551-557.

Reeves, H. (1989). The Victim Support Perspective, in Mediation and Criminal Justice: Victims, Offenders and Community, M. Wright \& B. Galaway (eds). London: Sage Publications.

Retzinger, S. \& Scheff, T. (1996). Strategy for community conferences: Emotions and social bonds. In B. Galaway \& J. Hudson (eds.) Restorative Justice: International Perspectives Monesy, NY: Criminal Justice Press. 
Tavuchis, N. (1991). Mea Culpa: A Sociology of Apology and Reconciliation. Stanford, CA: Stanford University Press.

Trenczek, T. (1990). A review and assessment of victim-offender reconciliation programming in West Germany, in B. Galaway \& J. Hudson (eds.) Criminal Justice, Restitution, and Reconciliation. Monsey, NY: Criminal Justice Press, pp. 109-124.

Umbreit, M. (1990). The meaning of faimess to burglary victims, in B. Galaway \& J. Hudson (eds.) Criminal Justice, Restitution, and Reconciliation. Monsey, NY: Criminal Justice Press.

Umbreit, M. (1994). Victim Meets Offender: The Impact of Restorative Justice and Mediation. Monsey, New York: Willow Tree Press, Inc.

Van Ness, D. \& Strong, K. H. (1997). Restoring Justice. Cincinnati: Anderson Publishing Co.

Wagatsuma, 11. \& Rosett, A. (1986). The implications of apology: law and culture in Japan and the United States, Law and Society Review, 20, 461-498.

Wright, M. (1991). Justice for Victims and Offenders: A Restorative Response to Crime. Bristol, PA: Open University Press.

Zehr, 11. (1990). Changing Lenses: A New Focus for Crime and Justice. Scottsdale, PA: Herald Press. 